\title{
Digital generation representatives of various professional success levels: psychological features
}

\author{
Vlada Pishchik ${ }^{1}$ and Margarita Postnikova ${ }^{2, *}$ \\ ${ }^{1}$ Don State Technical University, 344003, Gagarin Square 1, Rostov-on-Don, Russia \\ ${ }^{2}$ Northern (Arctic) Federal University named after M.V. Lomonosov, 163002, Severnaya Dvina \\ Embankment 17, Arkhangelsk, Russia
}

\begin{abstract}
The article presents the values of the individual psychological features of sales managers, reinforcing their professional effectiveness. The novelty lies in the fact that the individual psychological features of managers belonging to the digital generation, manifested in mental activity, interpersonal relationships and emotional reactions to the effects of the environment were studied. The following methods were used: the method of determining of the types of thinking and the level of creativity by G. Bruner, self-assessment of mental states by $\mathrm{H}$. Eysenck, diagnostics of interpersonal relationships by T. Leary, test «Motivational profile» by Sh. Richie and P. Martin, PSM25 by Lemour-Tessier-Fillion adapted by N.E. Vodopyanova, the technique of diagnostics of the type of the emotional reaction to the stimuli of the environment by V. V. Boyko. We calculated primary statistics and used the criteria analysis applying the Student's t-test. The results showed that: there are significant differences in individual psychological peculiarities of sales managers with different levels of professional efficiency. Effective managers are more aggressive, more closed, do not seek long-term relationships, financially oriented, have a need for achievements, recognition. Ineffective managers are more rigid, anxious, frustrated, aggressive, seek structured work, focused on long-term relationships, have a low need for self-improvement.
\end{abstract}

\section{Introduction}

The criteria for the evaluation of human activity are ephemeral and unstable, because the criteria and boundaries of modern reality are mobile and changeable. In this regard, the problem of evaluating the effectiveness of personnel becomes urgent. We wanted to assess the effectiveness of the personnel in connection with their personal features as representatives of a certain group of generations. The topic of employees belonging to different generations has become important and controversial in the research [1-2]. The researchers note that the managers of organizations want to understand the potential differences between generations and determine how to motivate, reward and manage them in the modern workplace [3-4, 5]. In this study we investigated managers belonging to the «information» generation (according

*Corresponding author: post-margarita@yandex.ru 
to the classification of W. Strauss, N. Howe [6] this is generation Y). Today one of the criteria for the effectiveness of specialists is speed and mobility, the ability to change [7]. The attention of various researchers is drawn to the analysis of generations in the workplace in various aspects. Researchers deal with the problems of generations in the connection with corporate culture. Comparison of managers of different cultures and generations is carried out by André van Hoorn [7], N. V. Twenge [5], R. Zemke, C. Raines [8] study of conflictness of generations at the work. Management of personnel of different generations, problems of motivation of representatives of generations at work are considered by M. Wong et al. [4], N. Campbell, S. M. Twenge, T. et al. [9]. Little attention is paid to the problems of differences within a group of one generation.

The term of «generation» is mostly understood as a social group. We have proved, based on a constructive approach, that generation is a form of cultural, collective representation [10]. Researchers pose the problem of accelerating of the changes of generations in the course of history. We believe that how quickly our ideas about generations change and spread, so quickly we show them certain expectations. The problem is also that managers have learned to interact with generations close to themselves, but new generations are waiting for them in the workplace.

We have identified different types of Russian generations in our classification, the score was from the time of perestroika in Russia [10]. These types of generations are represented now in organizations: «Traditional» — birth years are 1943-1961; «Transitional» — 1962 1983; «Information» - 1981-1999. We followed this classification in our research. The «information» generation is the post-Soviet generation - young employees who start to follow their professional path and who already have certain first professional achievements. They are from 20 to 38 year old now. Events that influenced on the formation of representatives of values: the consequences of the collapse of the USSR, the development of digital technologies and biotechnologies, «the Desert Storm», the first Chechen war, a new surge of terrorism. The concept of «decent life» for them is primarily about work and family. They are called «information aborigines» [11-12]. Independent Self-concept, individualistic value orientation, unstable way of the world, lifestyle, containing a wide repertoire of social practices, heterogeneous discourse dominates in the mentality of the representatives of the «information» generation. Employees of this generation are focused on flexible schedule and the possibility of remote work. A prestigious job and a high position is not an end in itself for them [10]. They prefer to develop horizontally rather than vertically, to gain wide experience in several areas. It remains to be seen: how homogeneous are the representatives of the «information» generation.

\section{Materials and Methods}

The study sample consisted of 160 people aged 20 to 27 years, bank employees, work experience up to 10 years. The "5+" personal efficiency assessment system (it includes: personal effectiveness, improvement of professional knowledge, optimization of the working process, teamwork, customer focus) developed by the personnel department was used to assess the professional efficiency of employees. According to the results of the assessment, the respondents were divided into two groups: effective (EM) and ineffective (IM) managers. The following methods were used: the method of determining of the types of thinking and the level of creativity by G. Bruner, self-assessment of mental states by H. Eysenck, diagnostics of interpersonal relationships by T. Leary, test «Motivational profile» by Sh. Richie and P. Martin, PSM25 by Lemour-Tessier-Fillion adapted by N.E. Vodopyanova, the technique of diagnostics of the type of the emotional reaction to the stimuli of the environment by $\mathrm{V}$. $\mathrm{V}$. Bo. 


\section{Results}

At the first stage of the analysis the Student's t-test was calculated. In the Table 1 there are the results of the study of the dominant types of thinking and the level of creativity.

Table 1. Type of thinking and level of creativity of managers with different levels of professional efficiency.

\begin{tabular}{|l|l|l|l|l|}
\hline & EM & IM & $\begin{array}{l}\text { Student's } \\
\text { t-test }\end{array}$ & $\begin{array}{l}\text { Significanc } \\
\text { e } \\
\text { of } \\
\text { differences }\end{array}$ \\
\hline Subject thinking & 6,37 & 7,20 & $-1,969$ & 0,054 \\
\hline Symbolic thinking & 10,9 & 6,77 & 6,837 & $0,000^{* *}$ \\
\hline Sign thinking & 8,63 & 8,50 & 0,282 & 0,779 \\
\hline Figurative thinking & 6,53 & 10,47 & $-11,326$ & $0,000^{* *}$ \\
\hline Creativity & 8,30 & 8,30 & 0,000 & 1,000 \\
\hline
\end{tabular}

Symbolic thinking prevails in the group of EM. These people have a mathematical mindset, they prefer to transform information using inference rules, in particular, algebraic rules or arithmetic signs and operations. The result is a thought expressed in the form of structures and formulas that fix the essential relationships between symbols. Figurative thinking prevails in the group of IM. These people have an artistic mindset, they prefer to transform information through actions with images. There are no physical restrictions on conversion for them. Operations can be carried out both sequentially and simultaneously. The result is a thought embodied in a new image.

In the Table 2 there are the results of the study of self-assessment of mental states.

Table 2. Self-assessment of mental states of managers with different levels of professional efficiency.

\begin{tabular}{|l|c|c|c|c|}
\hline \multicolumn{1}{|c|}{ Indicator } & EM & IM & Student's t-test & $\begin{array}{l}\text { Significance of } \\
\text { differences }\end{array}$ \\
\hline Anxiety & 6,47 & 8,77 & $-2,834$ & $0,006^{* *}$ \\
\hline Frustration & 5,43 & 7,60 & $-3,423$ & $0,001^{* *}$ \\
\hline Aggressiveness & 7,83 & 8,03 & $-0,486$ & 0,629 \\
\hline Rigidity & 7,23 & 9,10 & $-4,465$ & $0,000^{* *}$ \\
\hline
\end{tabular}

In the group of IM, the level of anxiety, frustration and rigidity is much higher than in the group EM. This indicates their propensity to experience anxiety, characterized by a low threshold of anxiety response, a tendency to a tense mental state that occurs as a result of real or imaginary interference that hinders the achievement of the goal, as well as the existing difficulties with adaptation to new conditions.

In the Table 3 there are the results of the diagnostics of interpersonal relationships in the group of EM. In the group of EM the real self coincides with the ideal self by 5 criteria.

Table 3. The results of the diagnostics of interpersonal relationships in the group of EM.

\begin{tabular}{|l|c|c|c|c|}
\hline Indicator & Real self & Ideal self & Student's t-test & $\begin{array}{c}\text { Significance } \\
\text { of differences }\end{array}$ \\
\hline Authoritarian & 8 & 8,2 & $-0,468$ & 0,643 \\
\hline Egoistic & 6,4 & 6,6 & $-0,425$ & 0,674 \\
\hline Aggressive & 4,9 & 6,9 & $-4,072$ & $0,000^{* *}$ \\
\hline Suspicious & 4,9 & 4,1 & 1,530 & 0,137 \\
\hline Submissive & 4,9 & 3,7 & 2,101 & $0,044^{*}$ \\
\hline Dependent & 3,7 & 3,8 & $-0,648$ & 0,522 \\
\hline Friendly & 5,5 & 5,7 & $-0,387$ & 0,702 \\
\hline Altruistic & 10,9 & 7,7 & 7,726 & $0,000^{* *}$ \\
\hline
\end{tabular}


There are no coincidences according to the criteria of aggressiveness, subordination, altruism. EM want to be more aggressive, less submissive, and altruistic.

In the Table 4 there are the results of the diagnostics of interpersonal relationships in the group of IM. In this group the real self does not coincide with the ideal self by all criteria. IM want to be more authoritarian, egoistic, aggressive and less suspicious, submissive, dependent, friendly, and altruistic.

Table 4. The results of the diagnostics of interpersonal relationships in the group of IM.

\begin{tabular}{|l|c|c|c|c|}
\hline \multicolumn{1}{|c|}{ Indicator } & $\begin{array}{c}\text { Real } \\
\text { self }\end{array}$ & $\begin{array}{c}\text { Ideal } \\
\text { self }\end{array}$ & $\begin{array}{c}\text { Student's } \\
\text { t-test }\end{array}$ & $\begin{array}{l}\text { Significance of } \\
\text { differences }\end{array}$ \\
\hline Authoritarian & 5,4 & 7,7 & $-3,969$ & $0,000^{* *}$ \\
\hline Egoistic & 4,5 & 6,6 & $-4,842$ & $0,000^{* *}$ \\
\hline Aggressive & 4,7 & 6,2 & $-3,612$ & $0,001^{* *}$ \\
\hline Suspicious & 5,6 & 2,7 & 6,369 & $0,000^{* *}$ \\
\hline Submissive & 9,1 & 2,4 & 8,758 & $0,000^{* *}$ \\
\hline Dependent & 6,7 & 3,2 & 4,831 & $0,000^{* *}$ \\
\hline Friendly & 7,6 & 4,2 & 6,933 & $0,000^{* *}$ \\
\hline Altruistic & 9,9 & 5,2 & 7,422 & $0,000^{* *}$ \\
\hline
\end{tabular}

In the Table 5 there are the results of the diagnostics of the motivation profile of managers with the different level of professional efficiency.

Table 5. Motivation profile of managers with the different level of professional efficiency.

\begin{tabular}{|l|c|c|c|c|}
\hline \multicolumn{1}{|c|}{ Indicators } & EM & IM & $\begin{array}{l}\text { Student's } \\
\text { t-test }\end{array}$ & $\begin{array}{l}\text { Significance of } \\
\text { differences }\end{array}$ \\
\hline Need for material reward & 9 & 5,2 & 7,315 & $0,000^{* *}$ \\
\hline $\begin{array}{l}\text { Need for good working } \\
\text { conditions }\end{array}$ & 4,6 & 3,2 & 1,918 & 0,060 \\
\hline Need for structuring work & 3,4 & 2,9 & 0,737 & 0,464 \\
\hline Need for social contacts & 4,2 & 3,6 & 1,237 & 0,221 \\
\hline Need for long term relationships & 2,2 & 4,4 & $-4,484$ & $0,000^{* *}$ \\
\hline Need for recognition & 5 & 4 & 1,904 & 0,062 \\
\hline Need for achievement & 4,6 & 3 & 3,128 & $0,003^{* *}$ \\
\hline Need for power & 0,76 & 2,1 & $-5,074$ & $0,000^{* *}$ \\
\hline Need for diversity & 5,8 & 5,9 & $-0,129$ & 0,898 \\
\hline Need for creativity & 2,2 & 4,8 & $-6,300$ & $0,000^{* *}$ \\
\hline Need for self-improvement & 4,9 & 6,4 & $-3,033$ & $0,004^{* *}$ \\
\hline Need for demand & 7,9 & 5,9 & 4,463 & $0,000^{* *}$ \\
\hline
\end{tabular}

In the group of EM there are needs for material reward and the desire to have a job with a good set of benefits and allowances, in good working conditions and a comfortable environment, there is a need to set challenging goals and achieve them; this is an indicator of the need to follow the goals and be self-motivated and in a sense of demand in an interesting socially oriented work.

The group of IM is dominated by the need to form and maintain long-term stable relationships, a small number of colleagues, a significant degree of closeness of relationships, trust, to be creative, analyzing, thinking employee, open to new ideas and the need for self-improvement, personal growth and development.

In the Table 6 there are the results of the study of the stress level of managers with the different level of professional efficiency. 
Table 6. Stress level of managers with the different level of professional efficiency.

\begin{tabular}{|c|c|c|c|c|}
\hline Indicator & EM & IM & $\begin{array}{c}\text { Student's } \\
\text { t-test }\end{array}$ & $\begin{array}{c}\text { Significa } \\
\text { nce of } \\
\text { differences }\end{array}$ \\
\hline Stress scale & 88,8 & 80,2 & $-2,180$ & $0,033^{*}$ \\
\hline
\end{tabular}

In the group of EM the stress level is higher than in the group of IM.

In the Table 7 there are the results of the study of the type of the emotional reaction to the stimuli of the environment (V. V. Boyko). In the group of EM the euphoric type of emotional response when the emotional system as a whole is configured on the positive incentives dominates.

In the group of EM employees the refractory type of emotional reaction dominates. The emotional system of perception succumbs to different influences - positive, negative and ambivalent. It chooses mainly ambivalent stimuli in the environment. At the same time, they «get stuck», remain in the form of experiences of an unpleasant sediment, reflections, hidden sadness, anger.

Table 7. Type of the emotional reaction to the stimuli of the environment.

\begin{tabular}{|l|c|c|c|c|}
\hline Indicator & EM & IM & $\begin{array}{c}\text { Student's t- } \\
\text { test }\end{array}$ & $\begin{array}{c}\text { Significance } \\
\text { of differences }\end{array}$ \\
\hline Euphoric & 21,8 & 25,6 & $-2,460$ & $0,017^{*}$ \\
\hline Refractory & 15,2 & 14,5 & 3,191 & $0,002^{* *}$ \\
\hline
\end{tabular}

At the second stage, a correlation analysis of the relationship of individual psychological indicators using the Pearson correlation coefficient was carried out. In the group of EM we discovered a strong direct relationship between indicators of anxiety and the need for material reward $\left(\mathrm{r}=0.540^{* *}\right)$, anxiety and the need for recognition $\left(\mathrm{r}=0.661^{* *}\right)$ and anxiety and the need to achieve the goals $\left(\mathrm{r}=0.589^{* *}\right)$. There is also a weak direct correlation between increased anxiety and frustration $\left(\mathrm{r}=0,414^{*}\right)$, anxiety and the need for good working conditions $\left(\mathrm{r}=0,377^{*}\right)$, anxiety and the need for structuring the work $\left(\mathrm{r}=0,414^{*}\right)$, anxiety and the need for long-term relationships $\left(\mathrm{r}=0,418^{*}\right)$, anxiety and the need for diversity $\left(\mathrm{r}=0,392^{*}\right)$. There are also strong inverse relationships between indicators of frustration and creativity $(\mathrm{r}=$ $-0.602 * *)$ and indicators of anxiety and the need for social contacts $(\mathrm{r}=-0.499 * *)$.

In the group of IM we discovered weak direct relationships between indicators of creativity and the need for structuring work $\left(\mathrm{r}=0.371^{*}\right)$, creativity and the need for longterm relationships $\left(\mathrm{r}=0.379^{*}\right)$, rigidity and the need for good working conditions $(\mathrm{r}=0.367 *)$, rigidity and the need for creativity $\left(\mathrm{r}=0.422^{*}\right)$. There is also a strong inverse relationship between indicators of anxiety and need for improvement $\left(\mathrm{r}=-0,465^{* *}\right)$ and a weak inverse relationship between indicators of anxiety and the need for diversity $(\mathrm{r}=$ $\left.0,416^{*}\right)$.

\section{Discussion}

Modern researchers are interested not just in studying a professional group, but in considering it within the context of belonging to a particular generation [13]. Digital generation is of special interest in scientific knowledge [14-15]. In this regard, our research allows to expand the psychological characteristics of the digital generation, whose representatives make up the majority of employees in one of the leading sectors of the economy - the banking sector.

The banking system plays a key role in economic development [16]. Therefore, it is relevant to study psychological characteristics of bank employees for personnel selection [17]. 
The banking system is quite rigid and highly organized for employees. Ongoing audits lead to increased stress and anxiety in employees [18-19]. Our findings confirmed it, showing that both EM and IM have high rates of anxiety and aggression. This may result in emotional burnout of employees. Aggressiveness discourages costumer focus, but it can promote aggressive marketing.

Bhardwaj, Mishra, and Jain (2020) identified factors that lead to higher levels of job satisfaction [19]. These factors relate to the management, remuneration, reorganization, promotion, work safety and relationships in the work environment. The survey results show that most bank employees are satisfied with the work culture, but wages and working hours remain their main concern. The results of our study confirmed these characteristics. For bank managers, financial remuneration and opportunities for career growth are essential. This correlates with the findings of our research on generational values (2011, 2019).

EM are more closed, financially focused, have a need for achievements and recognition, good working conditions. The turnover of highly qualified employees may explain the lack of commitment to a long-term relationship with the company. Their closeness explains the problems in teamwork. This result is comparable to the studies by Ali, Lei, and Wei [20]. The researchers have shown that a positive employee relations climate creates a social atmosphere, which encourages high employee involvement and an employee-centred culture.

We found out that symbolic thinking prevails in the group of EM and figurative thinking prevails in the group of IM. Our result goes well with the study of the system thinking of employees in Malaysia and Pakistan [21].

IM are more rigid, anxious, frustrated, strive for structured work, focused on long-term relationships, have the low need for self-improvement and the low need for good working conditions. It is obvious that IM are more focused on the performance of their duties. They do not seek self-improvement and workflow optimization. They can become good performers if the management is done well. It turns out that IM have a special role to play. The group of EM has a higher stress level than the group of IM. Our result is comparable to the research by Wang, Huang, Davison, Yang [22] on the role stressors of employees in organizations. This result is related to the motivation of managers. We find confirmation of this in the study by Belousova, Mochalova [23].

In the research we paid special attention to the emotional reactions of bank employees. The study of emotional response is important for various fields of professional activity [24].

We were surprised by the result that IM are rigid and creative. It might be due to their adaptation in such difficult working conditions and become a resource for employee development. Employee creativity is an important factor in the banking system [25].

\section{Conclusions}

Thus, based on the results obtained, the following can be stated:

Significant differences in individual psychological peculiarities (the type of thinking and the level of creativity, features of psychological state, the type of interpersonal relationships, professional motivation, emotional response to environmental stimuli and the level of psychological stress) of sales managers with different levels of professional efficiency were revealed. Effective managers are more aggressive, more closed, do not seek long-term relationships, financially oriented, have a need for achievements, recognition and good working conditions. Ineffective managers are more rigid, anxious, frustrated, aggressive, seek structured work, focused on long-term relationships, have a low need for self-improvement and a low need in good working conditions. 
There may be some possible limitations in this study. The findings do not take into account demographic factors and intergenerational comparison. Therefore, in the future, we plan to provide more differentiated results by gender and compare representatives of several generations.

The findings can be applied in the field of bank recruitment.

This work was supported by the Russian Foundation for Humanities (project № 18-013-00910 A).

\section{References}

1. D. P. Costanza, J. M. Badger, R. L. Fraser, J. B. Severt, P. A. Gade, Generational differences in work-related attitudes: A meta-analysis. Journal of Business and Psychology, 27, 375-394 (2012) doi: 10.1007/s10869-012-9259-4

2. D. P. Costanza, L. M. Finkelstein, Generationally based differences in the workplace: is there a there there? Industrial and Organizational Psychology, 8, $308-323$ (2015) doi: $10.1017 /$ iop. 2015.15

3. L. Cennamo, D. Gardner, Generational differences in work values, outcomes and person-organisation values fit. Journal of Managerial Psychology, 23, 891 - 906 (2008) doi: 10.1108/02683940810904385

4. M. Wong, E. Gardiner, W. Lang, L. Coulon, Generational differences in personality and motivation: do they exist and what are the implications for the workplace? Journal of Managerial Psychology, 23, 878 - 890 (2008) doi: 10.1108/02683940810904376

5. J. M. Twenge, A review of the empirical evidence on generational differences in work attitudes. Journal of Business and Psychology, 25, 201 - 210 (2010) doi: 10.1007/s10869-010-9165-6

6. W. Strauss, N. Howe, Millennials Rising: The next great generation (New York, 2009)

7. A. Hoorn, Individualism and the cultural roots of management practices. Journal of Economic Behavior \& Organization, 99, 53-68 (2014) doi: 10.1016/j.jebo.2013.12.020

8. R. Zemke, C. Raines, B. Filipczak, Generations at Work: Managing the Clash of Boomers, Gen Xers, and Gen Yers in the Workplace. New York, AMACOM (2012)

9. S. M. Campbell, J. M. Twenge, W. K. Campbell, Fuzzy But Useful Constructs: Making Sense of the Differences Between Generations. Work, Aging and Retirement 3(2), 130-139 (2017) doi: 10.1093/workar/wax001

10. V. I. Pishchik, Mentality of generations in fluid modernity. INFRA-M, Moscow (2019) doi:org/10.12737/monography_5ba0ee24675441.11909669

11. M. Prensky, Digital Natives, Digital Immigrants. On the Horizon, 9(5), 1-6 (MCB University Press, 2001) https://doi.org/10.1108/10748120110424816

12. A. K. Alan, E. T. Kabaday1, The Effect of Personal Factors on Social Media Usage of Young Consumers. Procedia - Social and Behavioral Science, 235, 595-602 (2016) doi: 10.1016/j.sbspro.2016.11.086

13. M. Y. Soto, M. V. Lugo, Multigenerational Differences in the Puerto Rican Workforce. Journal of Business Diversity, 13(1/2), 65-82 (2013)

14. N. Gerard, Millennial managers: exploring the next generation of talent. Leadership in Health Services, 32(3), 364-386 (2019) https://doi.org/10.1108/LHS-01-2018-0004

15. F. G. Arredondo-Trapero, L. E. Villa-Castaño, J. C. Vázquez-Parra, J. De la Garza García, Differences on self-perception of organizational pride and loyalty in Millennial, Generation X, considering gender and seniority variables. Business and Economic Horizons, 13(2), 270-286 (2017) http://dx.doi.org/10.15208/beh.2017.20 
16. T. V. Zaitseva, Banking System as a Growth Pole of the Global Economy: Historical Experience and Future Perspectives. In: Popkova E. (eds) Growth Poles of the Global Economy: Emergence, Changes and Future Perspectives. Lecture Notes in Networks and Systems, Springer, Cham, 73, 857-864 (2020) https://doi.org/10.1007/978-3-03015160-7_86

17. H. S. Kilic, A. E. Demirci, D. Delen, An integrated decision analysis methodology based on IF-DEMATEL and IF-ELECTRE for personnel selection. Decision Support Systems, 137 (2020) https://doi.org/10.1016/j.dss.2020.113360

18. P. Güngör, The Relationship between Reward Management System and Employee Performance with the Mediating Role of Motivation: A Quantitative Study on Global Banks. Procedia - Social and Behavioral Sciences, 24, 1510-1520 (2011) https://doi.org/10.1016/j.sbspro.2011.09.029

19. A. Bhardwaj, S. Mishra, T. K. Jain, An analysis to understanding the job satisfaction of employees in banking industry. Materials Today: Proceedings In press, corrected proof. Available online (2020) https://doi.org/10.1016/j.matpr.2020.04.783

20. M. Ali, S. Lei, X.-Y. Wei, The mediating role of the employee relations climate in the relationship between strategic HRM and organizational performance in Chinese banks. Journal of Innovation \& Knowledge, 3(3), 115-122 (2018) https://doi.org/10.1016/j.jik.2016.12.003

21. Ch. Sh. Akhtar, S. H. Awan, S. Naveed, K. Ismail, A comparative study of the application of systems thinking in achieving organizational effectiveness in Malaysian and Pakistani banks. International Business Review, 27(4), 767-776 (2018) https://doi.org/10.1016/j.ibusrev.2018.01.001

22. Y. Wang, Q. Huang, R. M. Davison, F. Yang, Role stressors, job satisfaction, and employee creativity: The cross-level moderating role of social media use within teams. Information \& ManagementIn press, corrected proof. Available online (2020) https://doi.org/10.1016/j.im.2020.103317

23. A. Belousova, Y. Mochalova, The Relationship of Thinking Style and Motivation Features of Sales and Advertising Managers. Behav. Sci., 10, 68 (2020) https://doi.org/10.3390/bs10030068

24. A. Korochentseva, D. Dautov, N. Khachaturyan, Features of ideas about professionally important qualities in food industry workers with differences in the severity of properties of the nervous system. In: E3S Web Conferences, XIII International Scientific and Practical Conference "State and Prospects for the Development of Agribusiness - INTERAGROMASH 2020”, 175, 15018 (2020) https://doi.org/10.1051/e3sconf/202017515018

25. Y. L. Yang, K. C. Peter, T. C. E. Cheng, Continuous improvement competence, employee creativity, and new service development performance: A frontline employee perspective. International Journal of Production Economics, 171(2), 275-288 (2016) https://doi.org/10.1016/j.ijpe.2015.08.006 